Res Publica. Revista de Historia de las Ideas Políticas

ISSN: $1576-4184$

http://dx.doi.org/10.5209/RPUB.59695

\title{
La justicia material en Max Weber
}

\author{
Annemaxmille Mendes-Quezado Ferrández*
}

Recibido: 25 de febrero de 2017 / Aceptado: 11 de diciembre de 2017

Resumen. El presente trabajo tiene como objetivo exponer y discutir la idea de justicia material desarrollada por Max Weber a lo largo de su obra Economía y Sociedad, así como los efectos de su pensamiento en la concretización de la justicia en la sociedad contemporánea. Se pretende hacer un análisis crítico de las premisas básicas del positivismo jurídico a la luz del pensamiento weberiano y llamar la atención sobre el carácter deontológico del Derecho y la necesidad de hacer efectivos los valores y las garantías constitucionales reconocidos como importantes para la sociedad y los objetivos políticos del Estado Democrático de Derecho. El desafío es superar las dificultades que obstaculizan la efectividad del Estado Democrático de Derecho y las condiciones que determinan la colonización del derecho por la política y economía en la sociedad para encontrar el mejor camino para que las leyes sean concretizadas debidamente. Palabras claves: Justicia material; Max Weber; positivismo jurídico; política; economía.

\section{[en] Material Justice in Max Weber}

\begin{abstract}
This paper aims to present and discuss the idea of material justice developed by Max Weber throughout his work Economy and Society, and its effects in justice in contemporary societies. It aims to make a critic of the basic premises of legal positivism in the light of the Weberian thought and draw attention to the ethical character of the law, and the need to enforce the values and constitutional guarantees recognized as important for the society and the political goals of democratic rule of law. The challenge is to overcome the difficulties impeding the effectiveness of democratic rule of law and the conditions that determine the influence of politics and economy in law to find the best way to ensure that laws are properly established.
\end{abstract}

Keywords: Material justice; Max Weber; legal positivism; policy; economy.

Sumario: 1. Introducción. 2. El concepto de justicia. 3. Max Weber: La racionalización formal y material del derecho. 4. Las fuentes del derecho material y la idea de justicia. 5. Conclusiones.

Cómo citar: Mendes-Quezado Ferrández, A. (2018). La justicia material en Max Weber, en Res publica 21.1, 31-46.

\section{Introducción}

Los conflictos contemporáneos, sean sociales, políticos, económicos o religiosos, en torno a la justicia, extrapolan los dilemas clásicos de la academia y envuelven intereses que se mezclan en sociedades cada vez más heterogéneas y multiculturales. Ese

\footnotetext{
* Universidad Complutense de Madrid annequezado@hotmail.com
} 
nuevo y dinámico contexto exige una reflexión filosófica sobre lo que configura la noción de justicia en el siglo XXI, así como sobre el papel del poder judicial en las transformaciones sociales.

Para responder a esas cuestiones, el presente artículo tiene como objetivo exponer y discutir la idea de justicia material desarrollada por Max Weber (1864-1920). Tomo en consideración sus trabajos vinculados al derecho: sobre todo, el capítulo dedicado a la Sociología del Derecho, en su obra Economía y Sociedad ${ }^{1}$ (1920), y el texto de La superación de la concepción materialista de la historia de Stammler (1907), así como los efectos de su pensamiento en la concretización de la justicia en la sociedad contemporánea.

Pretendemos analizar, en este trabajo, la extensión del pensamiento de Weber en sus trabajos sociológicos-jurídicos; comprender la idea de su teoría social y el carácter radical de su sociología alternativa; y defender la validez de su labor sociológica para responder a los actuales problemas del derecho. Con ello podemos comprender qué ocurre con muchas realidades constitucionales que, en lo que se refiere a la efectividad, permanecen muy distanciadas de las pretensiones normativas del texto constitucional. Es decir, son esencialmente "simbólicas".

De esta manera, este escrito se ocupa, en un primer momento, del examen del significado clásico de la idea de la justicia, muestra la versión clásica del concepto, y trata el tema, aunque no exhaustivamente, de la justicia distributiva o conmutativa, correctiva, natural, etc.

A continuación, nos adentraremos en el pensamiento de Max Weber, intentando extraer principios "substantivos" de justicia ${ }^{2}$, principios que nos permitan acercarnos al caso concreto para "humanizar la ley", evitando que el Derecho en su sentido estricto se convierta en la mayor injusticia.

De ese modo, y a fin de sustentar la tesis aquí propuesta, se busca destacar la dimensión crítica-normativa que la concepción weberiana de la ciencia adquiere en los desafíos jurídicos, éticos y políticos de nuestra época. En la perspectiva de Weber, la racionalización de las esferas sociales de la vida no era un fenómeno que se extendía solamente al ámbito económico y político, sino que recubría prácticamente todos los aspectos de la vida social en lo que él consideraba tiempos modernos.

Se pretende finalizar el presente artículo con una detallada reflexión sobre las fuentes del derecho material y la idea de justicia, siempre con apoyo en la perspectiva de Weber.

\section{El concepto de justicia}

Hay diversas maneras de aproximarse a la justicia, desde un enfoque jurídico, sociológico, político, psicológico o filosófico. Sea cuál sea el enfoque adoptado, lo más importante es no perder de vista la interdisciplinariedad que exige la materia y, con ello, conseguir una perspectiva integral de la idea de justicia. En el presente artículo adoptaremos el enfoque filosófico, sin olvidar los contextos sociológico, político y jurídico.

Título original Wirtschaft und Gesellschaft. Grundriss der verstehenden Soziologie. I.C.B. Mohr, 1922.

Justicia entendida como equidad. Del latín aequitas que es la traducción del término griego epiéikeia. 
Ese carácter interdisciplinar puede ser constatado a lo largo de la historia de la de filosofía ${ }^{3}$, en la que podemos encontrar la palabra justicia (Gerechtigkeit, en alemán;

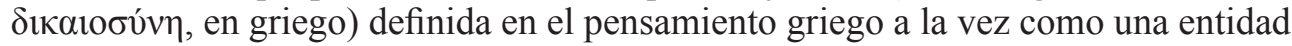
religiosa, política y ética.

Según Dworkin, la justicia es un concepto moral de orden superior, una institución que interpretamos y que tiene historia ${ }^{4}$ y por esta razón al tratar el tema debemos analizar las distintas concepciones de la justicia para ayudar a entender la complejidad y ambición filosófica de las teorías de la justicia. Es lo que pretendemos hacer a partir de ahora, sin pretensión alguna de agotar el asunto.

La noción de justicia está asociada a una amplia variedad de ideas, valores y sentimientos tales como: a) la justicia como virtud positiva: indignación y ante el mal, aborrecimiento, reivindicación, corrección de errores, compensación, reclamación, benevolencia o utilidad, bienestar o felicidad, legitimidad, eficiencia, libertad, igualdad, etc.; b) la justicia como virtud negativa: venganza, resentimiento de privación, conciencia de haber hecho algo malo, etc. ${ }^{5}$. Pero también, y principalmente, la justicia es vista como una "virtud pública o política", relacionada, por lo tanto, con el Estado, sus conductas, objetivos, organismos, funcionarios, etc. Y es justamente a partir de aquí que se establece la conexión, que nos interesa muchísimo, entre justicia (entendida como un valor social y político relativo), derecho y políticas públicas.

John Stuart Mill, en su tentativa de establecer una conexión entre justicia y utilidad, hace una incursión en la etimología de la palabra "justicia" y afirma que "en la mayoría, si no en todas las lenguas, la etimología de la palabra que corresponde a «justo» apunta claramente a un origen vinculado con las ordenanzas legales. [...] No puede haber duda de que la idée mère, el elemento primitivo en la formación de la noción de justicia fue la conformidad con la ley"6.

Según De Plácido e Silva, la palabra justicia es "derivado de justitia, de justus, y expresa, en el lenguaje jurídico, lo que se hace conforme al Derecho o según las reglas prescritas en la ley. Es, por lo tanto, la práctica de lo justo o la razón de ser del propio Derecho, pues por ella se reconoce la legitimidad de los derechos y se restablece el imperio de la propia ley"7. Y entre las sociedades organizadas, la justicia es el propio "fundamento de los poderes públicos, que se constituyen por delegación de la soberanía popular"'.

También es posible encontrar, en algunas argumentaciones jurisprudenciales, la idea de "justicia como valor", conectada y dependiente de la realización proporcional y razonable de los otros valores positivados. Aquí queda clara la importancia de los principios y de la idea de sistema jurídico. Es decir, no es posible hablar de justicia si son violados otros principios como la libertad o la igualdad.

\footnotetext{
J. Ritter, Historisches Wörterbuch der Philosophie, Band 3, G-H. Basel/Stuttgart, Schwabe \& Co, 1974, pp. $330-338$. R. Dworkin, El imperio de la justicia, Barcelona, Gedisa, 2008, p. 63.

T. Campbell, La justicia: los principales debates contemporáneos, Trad. Silvina Álvarez, Barcelona, Gedisa, 2002, pp. 15-16.

Cf. J. S. Mill, El utilitarismo. Madrid, Alianza Editorial, 1984, p. 108.

De Plácido e Silva, Vocabulário Jurídico. Rio de Janeiro, Forense, 2004, pp. 810-811.

Por eso el lema de Cicero: ubi non est justitia, ibi non potest esse jus. Donde no existe justicia no puede haber derecho. Cf. Decisión del Supremo Tribunal Federal (Brasil). HC 111198/MG. Relator Min. Ayres Brito. Juzgamiento 06/03/2012. "Justicia como valor, que se concreta mediante una cierta dosis de razonabilidad y proporcionalidad en la concretización de los valores de la libertad, igualdad, seguridad, bienestar, desarrollo, etc. Con lo que ella, justicia, solamente se realiza en la medida que los otros valores positivos se realicen por un modo peculiarmente razonable y proporcional".
} 
Desde el punto de vista de los valores, se puede decir que el concepto de equidad tiene mucha relación con la noción de justicia. En efecto, es un vínculo complejo que se da en sus diversas manifestaciones como justicia distributiva, conmutativa, natural, u otras.

Herbert Hart refuerza esa idea cuando afirma que el concepto general de justicia está relacionado con la equidad al apuntar que "las características distintas de la justicia y su conexión especial con el derecho comienzan a surgir si se observa que la mayor parte de las críticas hechas mediante el uso de las palabras «justo» e «injusto», podrían ser expresadas casi igual mediante las expresiones «equitativo» (fair) y «no equitativo» (unfair)" "10. Es decir, la equidad es una parte importante de la justicia.

En líneas generales, la justicia expresaría la rectitud, esquemática y racional, advenida en las leyes, que exige que las personas tengan los derechos jurídicos que deben tener; y la equidad expresa lo justo en el caso concreto, sin obviamente ir en contra de la ley, el justo legal. La equidad es una especie de justicia viva. En ese sentido, la justicia alude a la "aspiración del legislador", mientras que la equidad consiste en la elección por parte del "juez" de una norma justa para el caso concreto" ${ }^{11}$

La idea de equidad va más allá del tratamiento paritario y del tratamiento proporcional, es decir, puede imponer tanto la igualdad como la desigualdad, pues establece una "igualdad en la medida de nuestras desigualdades". En ese sentido, es una noción que permite justificar, por ejemplo, la "discriminación positiva" y "acciones afirmativas"12.

En este artículo partimos de la idea de que la filosofía analiza las tensiones entre la teoría y la práctica con el fin de aclarar esta relación, y tiene su tema central en el derecho establecido (derecho positivo) y su tensión con la moralidad, dónde se incluye la cuestión de la justicia. Nos interesa profundizar en el tema de la justicia y en esa relación con el derecho.

Entre los filósofos griegos, Platón fue el primero en tratar el tema de la equidad y su relación con la justicia. Nada más empezar la gran obra de filosofía política, $L a$ República, Platón comienza con una reflexión sobre el significado de la justicia. A partir de la lectura del Libro IV, queda claro que la noción platónica de lo justo coincide substancialmente con la que luego será la idea aristotélica de la virtud en relación con otros hombres, al establecer que la justicia consiste en que "cada uno haga lo que tiene obligación de hacer"13 no solo con relación a sí mismo, sino con la totalidad de la polis.

Sin embargo, Platón no puede tener otra idea de obligación que aquella que se deriva de la idea de bien. Con esta dependencia, Platón tiene herramientas suficientes para oponerse a los regímenes positivos tiránicos, en tanto inspirados en los sofistas. Con ello, se sitúa en el origen de la diferencia entre obligación buena y justa y obligación positiva, infundada y tiránica, ignorante y perversa. La diferencia queda establecida en este texto: "los oradores sabios y buenos consiguen que al Estado le parezca justo lo bueno, en lugar de lo malo. Pues lo que a un Estado le parece como justo y bueno, esto lo es también para él, mientras siga manteniendo tal opinión"14.

Es decir: aquí se reconoce la posibilidad de que el Estado tenga una opinión poco acertada acerca de sus propias normativas u obligaciones. El texto parece sugerir que

\footnotetext{
H. L. A Hart, El concepto de derecho. México, Editora Nacional, 1980, p. 197.

M. J. Falcón y Tella, Equidad, Derecho y Justicia. Madrid, Editorial Universitaria Ramón Areces, 2005, p. 262. Cf. M. J. Sandel. Justice: what's the right thing to do, New York, Farrar, Straus and Giroux, 2010, pp. 167-183. Platón, La República o El Estado. Edición Miguel Candel, Madrid, Espasa Calpe, 1993, p. 198.

14 Platón, Protágoras, 167c, apud H. Welzel. Introducción a la Filosofía del Derecho. Derecho natural y Justicia material, Montevideo, B de F Ltda., 2005, p. 11.
} 
el Estado puede tener una idea de justicia desviada cuando la justicia es obligación y el Estado puede tener una idea errónea y ajena al bien.

La idea de justicia es fundamental para el sistema ético de Aristóteles. En su visión hay dos clases de leyes: las que persiguen el provecho particular y las que persiguen el interés general. Las primeras han sido establecidas por los hombres, bien sea de forma escrita o no escrita, mientras que las segundas forman el derecho natural que dio origen y fundamento a la comunidad. Al tratar del tema de "justicia política", Aristóteles distingue la "justicia natural", lo que es justo por naturaleza y pertenece a la justicia no-escrita y la "justicia legal", lo que es justo por alguna disposición, lo meramente convencional ${ }^{15}$. Para Aristóteles hay otro significado de la justicia: la equidad. Un pasaje célebre de Ética a Nicómaco de Aristóteles nos trae la definición de equidad como "los decretos que se adaptan a los casos", un derecho de carácter casuístico, con función individualizadora y apreciadora del caso a caso. Aristóteles separó la idea de equidad (épieíkeia) de la noción de justicia, y colocó la primera en un nivel superior al de la justicia normativa, definiendo que "lo equitativo, si bien es mejor que una especie de justicia es justo, pero no es el sentido de la ley, sino una rectificación de la justicia legal"16.

Entre los contemporáneos, John Rawls defendió en cuestiones de justicia el racionalismo y el cognitivismo, con el replanteamiento de un discurso público democrático. Nada más empezar su libro, el filósofo afirma que "la justicia es la primera virtud de las instituciones sociales, como la verdad es de los sistemas de pensamiento"17. Rawls presenta su teoría de la justicia teniendo como idea central que "los principios de la justicia para la estructura básica de la sociedad son el objeto del acuerdo original"18. Partiendo de la "posición originaria"19, similar al estado de naturaleza, Rawls surgiere que al excluir todas las causas de parcialidad -actuar con el "velo de la ignorancia"- se produciría un resultado imparcial y equitativo. Se trata de una exigencia de imparcialidad que es clave para su teoría de la justicia como equidad. Y, para solucionar el problema de la elección que plantea la posición original, habrá que tener en cuenta los principios de la justicia, que desempeñarán su papel en nuestro razonamiento y conducta morales. Los principios de la justicia de Rawls son los siguientes: a) Principio de la libertad: cada persona ha de tener un derecho igual al más amplio sistema total de libertades básicas, compatible con un sistema similar de libertad para todos; b) Principio de la diferencia: las desigualdades sociales y económicas han de ser estructuradas de manera que sean para el mayor beneficio de los menos aventajados, de acuerdo con un principio de ahorro justo, y unido a que los cargos y las funciones sean asequibles para todos, bajo condiciones de justa igualdad de oportunidades ${ }^{20}$.

Las pretensiones de igualdad estructural de Rawls eran mal atendidas con la distribución justa de recursos básicos. En este sentido, la concepción de Rawls no estaba exenta de supuestos que conciernen al estatuto del sujeto. Esto se ve cuando Rawls trata el tema de la igualdad de la libertad y afirma que "el deseo de actuar con

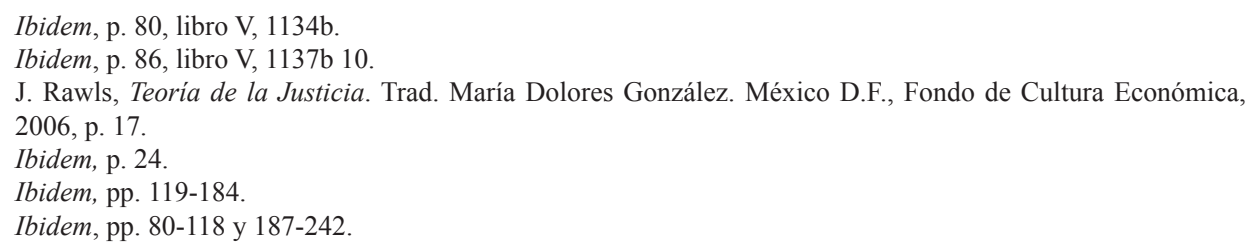


justicia se deriva en gran parte del deseo de expresar lo más exactamente posible lo que somos o lo que podemos ser, especialmente como seres libres y racionales con libertad de elegir", razón por la cual -en su opinión- Kant ${ }^{21}$ entiende que no actuar conforme a la ley moral no da lugar a un sentimiento de culpa, sino de vergüenza. Esto nos permitirá recordar la concepción de Immanuel Kant sobre la justicia.

Kant entiende, en contraste con la tradición antigua y medieval, que justicia no es principalmente una virtud sino una propiedad de la sociedad en el estado civil (Status Civilis). Él la considera el principio formal de la posibilidad de la condición jurídica entre los hombres. El proyecto kantiano aspira a liberar a los individuos de los supuestos dictados de la naturaleza humana y de la doctrina de la prudencia y convertirlos en racionalidades legisladoras, en sujetos establecedores del orden político y jurídico, a partir de una noción de moralidad y con ella de justicia, constituida por la propia comunidad política. Es decir, para que una sociedad sea reconocida como justa, tiene que tener libertad, independencia e igualdad entre los miembros de la comunidad. La tesis kantiana concede prioridad incondicional a la forma del progreso jurídico sobre el progreso material y, por eso, José Luis Villacañas afirma que, en ese sentido, "la forma democrática ya impone en germen el contenido distributivo de la justicia. Esta afirmación nos conduce a la idea de que la justicia intraestatal es el fin interno impuesto a la forma normativa del derecho por el mero hecho de originarse a través de la publicidad"22.

Toda esta tradición queda asimilada en la teoría de Habermas, cuya idea de justicia no está relacionada con aspectos teleológicos sino deontológicos y, por lo tanto, conectada con "la moral", entendida como normas universales que tienen que ver con valores. Es decir, la justicia es "un predicado sobre la validez de los enunciados normativos universales que expresan normas morales generales", normas que son igualmente buenas para todos, como la máxima del principio de universalización. Este filósofo entiende que el derecho tiene un papel crucial de cohesión, al proporcionar "expectativas estables" y ve la "justicia relacionada con el derecho como un subsistema de la sociedad que tiene particularmente que ver con la función de la interacción social" 23 . La concepción habermasiana de la justicia se presentaría como un requisito de la racionalidad comunicativa, en la medida en que esta implica igual participación en el diálogo que pretende la búsqueda de la verdad y justicia objetivas.

Hasta aquí podemos destacar dos primeras conclusiones. En primer lugar, que hay una cierta complejidad en la idea misma de justicia. En segundo, que hay muy buenas razones para que las ideas de justicia material y de bienestar social ocupen un lugar de máxima importancia en el discurso jurídico, en el análisis crítico del papel del Derecho y de otras instituciones públicas o sociales en nuestra sociedad.

\section{Max Weber: La racionalización formal y material del derecho}

Max Weber utiliza el concepto de racionalidad en una amplia variedad de contextos para referirse a ciertos aspectos de la acción, decisión y visión del mundo. Su teoría

21 Afirma Rawls que "el objetivo principal de Kant es profundizar y justificar la idea de Rousseau de que la libertad consiste en actuar de acuerdo con una ley que damos a nosotros mismos" (Ibidem, p. 240).

22 J. L. Villacañas, Res Publica. Los Fundamentos normativos de la política, Madrid, Ediciones Akal, 1999 , p. 90.

23 T. Campbell, La justicia: los principales debates contemporáneos, Trad. Silvina Álvarez. Barcelona, Gedisa, 2002, p. 234. 
de la racionalización de la modernidad está expuesta de forma detallada en Economía y Sociedad, obra póstuma en la que realiza un estudio profundo sobre la constitución social de las sociedades capitalistas y sus transformaciones en los diversos ámbitos, especialmente el económico y el jurídico. Observa los cambios que ocurrieron en la ciencia y, sobre todo, en el Estado de derecho, e interpreta las diversas dimensiones de sentido que están en la base de las estructuras sociales.

Tal constatación, en la perspectiva de Habermas, abre espacio para la libertad y la autonomía, permitiendo la actuación de la "acción comunicativa" en el entendimiento común sobre las normas y valores universales, así como en la solución de los conflictos sociales. Y aquí empieza toda una reflexión crítica por parte de Habermas sobre el pensamiento weberiano, por entender que la teoría de Weber capta apenas el "saber racional con relación a los fines", además de utilizar un concepto complejo y al mismo tiempo restricto de racionalidad.

La concepción de la sociedad construida por Weber implica una separación de las diversas esferas que la constituyen -como lo económico, lo religioso, lo político, jurídico, social, cultural- cada una con una operación lógica particular. El agente individual es la unidad de estos ámbitos sociales, la única entidad capaz de dar sentido integrador a sus acciones.

En el pensamiento weberiano, la modernización de la sociedad es entendida como un proceso "histórico y gradual de racionalización", que abarca dos aspectos: la racionalización religiosa y la racionalización social, cuyo análisis de la "acción social" representa su punto central, el elemento constitutivo. Según Weber, la acción social puede ser: racional con arreglo a fines, racional con arreglo a valores, afectiva y tradicional. Ahora bien, la "acción social" y también la "relación social" pueden orientarse por la representación de la existencia de un orden legítimo y eso ocurre cuando estamos delante de lo que él llama "validez del orden". Al "contenido de sentido" de una relación social le llamamos "orden" cuando la acción se orienta por "máximas" que pueden ser señaladas. Y sólo hablaremos de una "validez" de este orden cuando la orientación de hecho por aquellas máximas tiene lugar porque en algún grado significativo son válidas para la acción, es decir, como obligatorias o como modelos de conducta ${ }^{24}$.

Recordemos que, según Weber, un orden legítimo puede llamarse: convención, cuando su validez está garantizada externamente por la probabilidad de que una conducta discordante tenga que enfrentarse con una reprobación general en el seno del grupo. Sin embargo, se llama derecho cuando la validez del orden está garantizada por la probabilidad de la coacción ejercida por un "cuadro de individuos" encargado de esa función. Lo decisivo en el concepto de orden de derecho es el "cuadro coactivo", la posibilidad de castigar su transgresión. El derecho es el refuerzo coactivo de la validez, pero no su substitución ni su anulación.

En este sentido, el derecho supone el poder, aunque el poder no requiere derecho. Según Weber, poder significa "la probabilidad de imponer la propia voluntad, dentro de una relación social, aun contra toda resistencia y cualquiera que sea el fundamento de esa probabilidad" y dominación debe entenderse como "la probabilidad de encontrar obediencia a un mandato de determinado contenido entre personas dadas" 25 . La diferencia entre poder y dominación tiene que ver con la naturaleza puntual, in-

Ibidem, p. 25.

Ibidem, p. 43. 
forme, personal, difusa del primero, frente a la naturaleza objetivada y reglada de la segunda. La dominación implica una fundamentación estable del poder, pero no toda dominación es por sí legítima, a esta le es intrínseca la afirmación de su validez. Y esto implica algún grado de reconocimiento de su justicia o su derecho a dominar.

Como toda acción, la dominación legítima se puede asentar en cuatro aspectos. Así, señala Weber que la dominación legítima puede ser justificada a través de principios de autoridad racional de valores, por su conciencia de valor; b) por principios racionales según fines, que establece dependencia con consideraciones utilitarias de ventajas e inconvenientes por parte de quien obedece; c) tradicionales: dependencia con relación a las costumbres; y d) afectivos: basados en el puro afecto, en la mera inclinación personal del súbdito. Sin embargo, en la relación de dominación, por cuestiones de estabilidad, se acostumbra a apoyarla internamente sobre bases jurídicas, donde se funda su legitimidad, en una mezcla inseparable a veces de validez y utilidad, de tradición y hábito. De aquí deriva la célebre división de los tipos de dominación en la que no vamos a entrar. Solo nos interesa el tipo de dominación legal, en la que rige la conciencia de la validez del estatuto legal.

En este aspecto, conviene afirmar que Max Weber establece un nexo entre racionalización y legalización, y por eso, a partir de la teoría weberiana del proceso de racionalización formal del poder estatal, se deriva una especie de Estado burocrático cuya legitimidad tiene su base en el "poder legal", regulado por el Derecho en todos los niveles. Weber, partiendo de la idea de que la humanidad proviene de un universo habitado por la magia, y percibiendo que alcanzó un estado racionalizado, material, técnico y manipulado por la ciencia, entiende que llegamos al denominado "desencantamiento del mundo". Ahí es donde la dominación legal puede mostrar todo su sentido.

Desde este punto de vista, el derecho ocupa un lugar destacado en la teoría de la racionalización weberiana. La sociología jurídica weberiana descansa en un cierto número de distinciones entre derechos entre las que destaca la distinción entre Derecho formal y Derecho material y, a través de ello, la idea de justicia formal y material. La idea formal responde a una racionalización basada en motivos lógicos de coherencia y rigor, que no está exenta de dignidad en la autopercepción de las élites. Pero la sociología del derecho de Max Weber tiene como idea central el fenómeno de la racionalización y busca comprender el papel de la política, de la economía y de la religión en la evolución histórica del Derecho, encontrando así un sentido a todo ese proceso histórico y entender, con ello, el comportamiento fáctico relevante de los individuos con relación a las normas vigentes; el sentido y la relación entre las conductas humanas y el orden jurídico; su validez y eficacia social. Él busca comprender el movimiento de racionalización jurídica, observando si constituye un progreso del orden jurídico o más bien un perfeccionamiento de la técnica jurídica, una mera mejora lógica de la norma o una mejora en su capacidad de vincular los sujetos a los órdenes jurídicos.

Max Weber, en su análisis sobre la modernidad, parte de la idea de que la "racionalización" conlleva el "desencantamiento del mundo"26, exactamente por el efecto de despersonalizar las relaciones sociales, de limitar la libertad humana, de cambiar

26 El referido proceso se da especialmente a través del progreso de la ciencia y de la técnica que resulta en la descreencia, por parte de los hombres, en los espíritus, en el sentido profético y sagrado. 
la autonomía en "jaula de hierro"27 y de mecanizar la vida humana. En esta perspectiva, Weber, al enfrentarse a la cuestión de la racionalización jurídica en el Estado moderno, se da cuenta de la crisis del Estado liberal de Derecho precisamente por estar orientado por una "racionalidad técnica instrumental", que lo ha aislado.

En la perspectiva de la "sociología comprensiva" 28 de Weber, el derecho es una forma típica de orden legítimo caracterizado por la existencia de un "aparato de coerción", una institución creada con el fin de hacer respetar el orden legal y castigar cualquier infracción. Pero para ello, para que no sea desnuda fuerza, el orden tiene que ser legítimo, esto es, visto como válido. Por eso diferencia el Derecho formal (sistematizado en las normas) como siendo "el conjunto del sistema del Derecho puro cuyas normas obedecen únicamente a la lógica jurídica, sin intervención de consideraciones exteriores al Derecho" y, por otro lado, el Derecho material (más casuístico) que tiene en cuenta "elementos extrajurídicos y se refiere, en el curso de sus juicios, a los valores políticos, éticos, económicos o religiosos".

De donde resultan, como dice Julien Freund, dos maneras de concebir la justicia: "una se atiene exclusivamente a las reglas del orden jurídico -es justo lo que está establecido y conforme a la letra o a la lógica del sistema- y la otra tiene en cuenta la situación, las intenciones de los individuos y las condiciones generales de su existencia" ${ }^{29}$. Por eso mismo, el juez tiene dos formas de pronunciarse: limitándose a aplicar estrictamente la disposición legal o intentando comprender lo que parece más equitativo, preocupándose de que su decisión sea efectivamente "justa".

Dentro de esta clasificación, los especialistas en Weber distinguen cuatro "tipos ideales" de Derecho: a) Derecho irracional y material, basado en puros valores emocionales, en los sentimientos (justicia dictada por un déspota o por la inspiración del juez o su voluntad); b) Derecho irracional y formal: tiene en cuenta normas que escapan a la razón como los juicios de Dios de la Edad Media; c) Derecho racional y material: basado en la voluntad política o ideología, mediante una interpretación abstracta basada en mandatos de contenido general tales como "imperativos éticos, reglas utilitarias y de conveniencia, o postulados políticos que rompen tanto con el formalismo de las características externas como con el de la abstracción lógica" ${ }^{30}$ y que activan las instancias y las fuentes de la validez, d) Derecho racional y formal: basado en los conceptos abstractos originados por el pensamiento jurídico.

Por lo tanto, de aquí se extraen dos tipos de tensiones entre racionalidad e irracionalidad y entre formalidad y materialidad. Weber señala, de acuerdo con esto, dos vías de racionalización del derecho: a) la generalización que puede partir de una racionalización material; y b) la sistematización que parte de una racionalización lógica.

Como conclusión, hay que señalar que la racionalización del Derecho se vincula directamente al cuestionamiento de cuál es la función del Derecho en la sociedad actual. Para eso, Weber parte de la distinción entre racionalización formal y material del Derecho -los "tipos ideales" del Derecho-. Es decir, por un lado, la existencia de las normas jurídicas que responden a la lógica interna del sistema jurídico, cuyo

27 M. Weber, Wirtschaft und Gesellschaft, v.e. Economía y Sociedad. Esbozo de sociología comprensiva, Madrid, Fondo de Cultura Económica, 1993. La ética protestante y el espíritu del capitalismo.

28 Se trata de una ciencia que trata de comprender de forma interpretativa la acción social de los individuos (comprensión del sentido y explicación causal de la acción social).

29 Ibidem, pp. 226-227.

30 Cf. M. Weber, Economía y Sociedad, op. cit., p. 511. 
criterio de justicia es estrictamente formal, traducida por la "racionalidad instrumental", que atiende a la coherencia lógica; y por otro, la racionalidad material que confiere importancia a elementos extrajurídicos. En ese contexto se establece una especie de tensión entre legalidad y justicia.

Según Boaventura de Sousa Santos, debemos preguntarnos si de este modo podemos platearnos las cuestiones de la legalidad y la legitimidad. Max Weber identifica tres lógicas de racionalidad que constituirían el pilar de la emancipación: a) la racionalidad estético-expresiva de las artes y la literatura, que impulsa la creación de futuros posibles a través de la estética; b) la racionalidad cognitivo-instrumental de la ciencia y tecnología, que también crea futuros posibles al liberar a los individuos de los límites establecidos; y c) la racionalidad moral-práctica de la ética y del imperio de la ley, que permite la creación de futuros posibles "al transformar las nuevas exigencias éticas de libertad, igualdad y fraternidad en imperativos políticos y en exigencia jurídicas" 31 .

La "referencia a los valores", indispensable para Weber en todos los casos, es un principio de elección que sirve para establecer cuáles serán los problemas, los aspectos de los fenómenos, es decir, el campo dentro del cual la investigación se llevará a cabo de forma científica con la finalidad de alcanzar las explicaciones causales de los propios fenómenos. Weber distingue, claramente, entre juicios de hecho y juicios de valor como "aquello que es" y "aquello que debería ser"32 y defiende que la racionalidad con arreglo a valores es siempre irracional en la medida en que "el valor que le mueve se eleve a la significación de absoluto"33. Pero no es irracional a su vez en el sentido absoluto de arbitrariedad o de invención o capricho. El valor siempre tiene en su base un bien humano, apreciable por cualquiera. Es irracional en la medida en que se eleve a absoluto, en la medida en que niegue otros bienes y valores. La pregunta es cuál debe ser el saber que oriente la racionalidad material del derecho de tal manera que inspire una dominación legitima.

Nada más empezar el estudio de la economía y los diversos órdenes, Weber trata del orden jurídico y del orden económico y señala que, cuando se habla de "derecho", "orden jurídico" y "preceptos jurídicos", debe tenerse en cuenta la distinción entre la consideración jurídica, que se pregunta lo que idealmente vale como derecho, y la sociológica, que "se pregunta lo que de hecho ocurre en una comunidad en razón de que existe la probabilidad de que los hombres que participan en la actividad comunitaria, sobre todo aquellos que pueden influir considerablemente en esa actividad, consideren subjetivamente como válido un determinado orden y orienten por él su conducta práctica" 34 . Este punto se pregunta no solo por la posible dimensión coactiva, sino por la dimensión jurídica y legítima del derecho.

En la administración de la justicia, Weber busca la vía "substancial" que atribuye al juez, sobre todo en los casos en que las leyes "enmudecen". Ve aquí una actividad creadora del derecho, entendiendo que "el precepto jurídico" "es lo secundario, lo obtenido por abstracción partiendo de las decisiones concretas, las cuales representan el producto de la actividad de los juristas y constituyen la verdadera base del de-

31 B. De Sousa Santos, Sociología Jurídica crítica: para un nuevo sentido común del derecho, Madrid, Editorial Trotta, 2009, p. 32.

32 G. Reale y D. Antiseri, Historia da filosofia, São Paulo, Paulus, 2003, p. 75.

33 Cf. M. Weber, Economía y Sociedad, op. cit., p. 21.

$34 \quad$ Ibidem, p. 251. 
recho vigente" ${ }^{35}$. Sin embargo, a través del constante aumento del derecho legislativamente formulado y de las codificaciones sistemáticas, alerta Weber que los juristas académicos se sienten fuertemente amenazados en su significación.

Esta disminución de la relevancia de los juristas académicos se compensa con la mayor influencia no tanto del legislador, sino del sistema político. En el pensamiento weberiano es evidente un estrecho vínculo entre el derecho y el sistema político. Después de la crisis del liberalismo y con el surgimiento de la democracia social, la participación del Estado en la sociedad se intensifica y, con ella, la actividad del operador del derecho, especialmente la del político plebiscitario, pasa a ser vista como algo más complejo, una actividad capaz de garantizar la efectividad de la tutela de los derechos y la materialidad de un proceso justo que tiene como fin la paz social.

De igual forma, se encuentran mutua e íntimamente relacionados el orden jurídico y el orden económico y, en esta relación, el orden jurídico, afirma Weber, "no significa un cosmos lógico de normas «correctamente» inferidas, sino un complejo de motivaciones efectivas del actuar humano real" 36 . Este complejo conjunto de motivaciones es el que se dinamiza en la democracia de masas, centrado en el líder plebiscitario carismático. Su ausencia, sitúa al juez en la primera línea de fuego en la racionalización material.

Queda claro que el poder judicial no puede permanecer indiferente a la transformación y a los problemas sociales, sobre todo si consideramos la creciente visibilidad social y el protagonismo judicial debido al "activismo de los Tribunales Constitucionales". Es decir, cada vez queda más claro que el Estado de Derecho y el sistema judicial constituyen componentes fundamentales para el sostenimiento de la legitimidad de la democracia representativa. Interesa aclarar con energía que aquí no se ha pretendido extinguir toda vinculación jurídico-formal, que tiene su importancia en el "cálculo de las probabilidades", por ejemplo; sino que solo pretendemos subrayar el pensamiento de Weber en el sentido de que "el racionalismo jurídico significa algunas veces un «empobrecimiento» o disminución de la riqueza de las formas, aun cuando en la actualidad suele fácilmente exagerarse este fenómeno"37.

Es lógico que Weber desembocara en el tema de la influencia que ejercen las formas políticas de dominación sobre las cualidades formales y materiales del derecho. En la "dominación burocrática racional" el proceso de control social de comportamiento es "caracterizado porque se ejercita mediante pautas normativas generales que habilitan la predicción de las circunstancias en que se va a inutilizar la coacción que define el dominio o en las que se van a producir los cambios normativos. Lo que vendría a posibilitar que el entorno social se torne previsible y se reduzca la incertidumbre" 38 . En la segunda forma de legitimación, el juez carismático, como agente representante del poder estatal responsable del ejercicio de la función jurisdiccional y representante de los valores trascendentales de la comunidad, es considerado un individuo capaz de producir justicia y, por lo tanto, está imbuido "en una actividad verdaderamente «creadora», es decir, portadora de nuevo derecho, [esquema en el que] sólo se han colocado los juristas de tipo

\footnotetext{
Ibidem, p. 653.

Ibidem, p. 252.

Ibidem, p. 550.

Ibidem, p. 195.
} 
profético" ${ }^{39}$. Según Weber, la dominación carismática, cuya legitimidad depende de la "creencia efectiva" y de la "voluntad de los dominados", esa apelación al carisma del líder político es necesaria. La autoridad natural del carisma en las sociedades de democracia de masas debe asociarse a la eficacia técnica de la burocracia racional para así preservar la "sociedad abierta". En este sentido, Weber quiere equilibrar los aspectos carismáticos e institucionales y supone una racionalización material en el contexto de una no abandonada racionalización formal.

Este equilibrio es básico en el racionalismo europeo. Así, Weber afirma que el hecho de que, en la práctica, en algunos países como Estados Unidos y Gran Bretaña los precedentes tengan una importancia altamente diferenciada nos demuestra que se ha conservado todavía el genuino carácter carismático de la administración de justicia. El carisma genuino a través del líder plebiscitario sería un intento de "reencantamiento" del Estado democrático de derecho, cuyo reconocimiento por la comunidad de creyentes crearía un deber de cumplir "lo que en verdad se ha dicho".

Para Max Weber

el carisma es la gran fuerza revolucionaria en las épocas vinculadas a la tradición. A diferencia de la fuerza igualmente revolucionaria de la ratio que, o bien opera desde fuera por transformación de los problemas y circunstancias de la vida $-\mathrm{y}$, por tanto, de modo mediato, cambiando la actitud ante ellos- o bien por intelectualización, el carisma puede ser una renovación desde dentro, que nacida de la indigencia o del entusiasmo, significa una variación de la dirección de la conciencia y de la acción, con reorientación completa de todas las actitudes frente a las formas de vida anteriores o frente al "mundo" en general ${ }^{40}$,

cuya legitimidad reposa en la concepción del ser o deber de aquellos llamados a la misión carismática que reconozcan su cualidad y actúen de acuerdo con eso.

El progreso de la "burocratización" ${ }^{41}$ y de la formulación de normas jurídicas de tipo formal implica una posición del juez meramente de intérprete y aplicador de las normas, sin darse cuenta de la creación efectiva que debe generar su actividad. En lo que toca a la administración de justicia, tal estructura crea la base para la organización de un "derecho sistematizado y racional fundado en leyes", una administración de justicia de "tipo burocrático", cuya creencia máxima está en la "santidad del formalismo jurídico" sin más y en que los miembros de la judicatura son dependientes de los poderes políticos dominantes.

Lo que pretende Weber es que la práctica jurídica sea algo más que un simple medio de lucha de intereses, y con ello, Weber ha reconocido una fuerte vinculación entre democracia, autoridad, justicia material, concepciones de fines (no de medios) y la exigencia fundamental de que el sistema jurídico no sea un dispositivo incomprensible para legos, sino una administración comprensible. Esa comprensión es la que posibilita una justicia material que permite la emergencia de una experiencia común de lo justo.

$39 \quad$ Ibidem, p. 659.

$40 \quad$ Ibidem, pp. 196-197. Lo siempre nuevo, lo extracotidiano y lo nunca visto constituyen fuentes de la devoción personal.

${ }^{41}$ La peculiaridad específica de la burocracia, tan bienvenida al capitalismo, dirá Weber, es que se desarrolla en mayor grado cuanto más se "deshumaniza". 


\section{Las fuentes del derecho material y la idea de justicia}

Siempre ha sido un dogma del positivismo jurídico que la fuente principal del Derecho en el Estado moderno debe ser la ley, la norma abstracta y general, promulgada por un órgano legítimo y creada mediante un procedimiento específico, el "Derecho del Estado". Sin embargo, otras fuentes del Derecho han surgido debido a la transformación de nuestra sociedad, a través de la propia dinámica de los hechos sociales, es decir, del surgimiento del "Derecho social". Para conseguir responder al fenómeno de la praxis, también la propia actividad creadora del juez, la "significación de la fijación legislativa" y la jurisprudencia se revelan como fuentes del Derecho.

Sin duda alguna, para tratar del tema del origen o fuente material de las normas no sólo no se puede abstraer, sino que se debe tener en cuenta los precedentes jurisprudenciales, que permanecen en contacto con la vida del "jurista práctico"; y la "voluntad del legislador", que sopesa los intereses sociales, la situación social, la crisis económica, la emergencia política, las ideas y teorías de justicia, etcétera. Por eso, Weber defiende una "nueva orientación de la acción comunitaria" que coloca a los jueces ante situaciones nuevas a las que dar respuesta, que responden a ideas de valor, no de medios, y que soportan su propia racionalidad.

Sin embargo, Weber alerta sobre la existencia de un "irracionalismo valorativo" con relación a los precedentes y la "reimplantación de un criterio axiológico objetivo", afirmando que "la doctrina moderna sobre las fuentes del derecho ha destruido tanto el concepto semimístico del «derecho consuetudinario» que forjó la Escuela Histórica, como la noción, igualmente histórica, de una «voluntad del legislador», obtenible a través del estudio del proceso de formación de la ley" ${ }^{42}$. Es decir, el jurista no tiene que ver con el legislador, sino con la ley "pura" y "abstracta". Este irracionalismo valorativo, en el fondo, es completamente diferente de la producción de novedad que vimos en el párrafo anterior, porque mientras que allí los jueces se atienen al sentido comunitario objetivo, aquí se basan en instancias inverificables, como el espíritu del legislador o de los antecedentes, que no llevan a un "criterio axiológico objetivo". Esto no sucedía en la situación objetiva ante la que el juez tiene que responder, cuando viene avalada por la nueva orientación de la acción comunitaria.

Weber entiende que el tipo más puro de validez racional con arreglo a valores está representado por el derecho natural, pero aclara que la forma de legitimidad más corriente hoy es la "creencia en la legalidad: la obediencia a preceptos jurídicos positivos estatuidos según el procedimiento usual y formalmente correctos" ${ }^{\text {" }}$. Con ello, Weber se dirige ineludiblemente al problema de la relación entre legalidad y derecho natural, y, por tanto, legitimidad racional conforme a valores. Por eso es necesario algo más que legalidad, y Weber nos recuerda la importancia de la "acción social" y de las "sociedades abiertas".

Para Weber, el "derecho natural" es la forma específica de legitimidad del ordenamiento jurídico revolucionariamente creado y puede ser definido como "el conjunto de normas vigentes preeminentemente frente al derecho positivo y con independencia de él, que no deben su dignidad a un establecimiento arbitrario, sino que por el contrario, legitiman la fuerza obligatoria de éste" ${ }^{\text {"4 }}$. Si sustituimos revolución por

\footnotetext{
$42 \quad$ Ibidem, p. 654.

43 Ibidem, p. 30.

44 Ibidem, p. 640.
} 
novedad, comprendemos que, para Weber, el derecho natural no había perdido su capacidad de presionar a la legalidad y concretar materialmente la idea de justicia. Así, Weber afirma que "todos los dogmas iusnaturalistas han influido siempre con mayor o menor intensidad sobre la creación y la aplicación del derecho" 45 , sea desde el punto de vista formal, fortaleciendo el poder de la lógica en el pensamiento jurídico, sea desde el punto de vista material, derivando la legitimidad del propio derecho creado.

A fin de cuentas, la eficiencia de la justicia, las políticas judiciales o la relación de la justicia serán medidas a través de las realidades sociales, como son la práctica judicial y cuál es su relación con la vida de las personas, con sus reales capacidades. Sólo de ese modo es posible hacer una aproximación entre lo que se idealizó en las normas y la realidad. La investigación reciente de lo que ha venido a llamarse "perspectiva de la capacidad" 46 , que apunta la relevancia central de la desigualdad de capacidades en la evaluación de las disparidades sociales, encaja directamente con la comprensión de la justicia material que desarrollamos en este trabajo, pues establece "el énfasis en las vidas reales para la evaluación de la justicia" ", en la vida que la gente es capaz de vivir. Desde el punto de vista del "enfoque de las capacidades", es imprescindible añadir como parte de las "circunstancias de la justicia" las generalizadas e innegables condiciones humanas de dependencias y vulnerabilidades, de explotación y dominación. También es imprescindible establecer lo mejor y lo peor de la sociedad en términos de funcionamientos y capacidades, analizar lo que las personas son capaces de hacer y de $\operatorname{ser}^{48}$.

De hecho, el cambio de rumbo que propone Amartya Sen tiene un impacto directo en la filosofía política y moral, así como en los debates contemporáneos sobre derecho, economía y política en la medida que defiende que la única salida del camino hacia la justicia es ver el "desarrollo como expansión de capacidades". Pues, como defiende Paul Ricoeur, solamente como ciudadanos llegamos a ser hombres ${ }^{49}$ $\mathrm{y}$, de esta manera, se puede hablar de dignidad humana.

Weber es consciente de que, donde existe la comunidad jurídica, "el carácter formal de derecho y de la aplicación del mismo es ampliamente cuidado, pues la aplicación no depende del arbitrio o de los sentimientos y emociones de aquellos para quienes vale, ya que no pretende «servirlos», sino dominarlos, por lo que aparece como un producto de la revelación de los poseedores de la sabiduría jurídica" ${ }^{50}$. Pero esa sabiduría, como todo auténtico poder carismático, tiene que "corroborarse" por su fuerza convincente, algo que sólo se logrará si es capaz de configurar e identificar lo justo para el común de los ciudadanos.

La historia de la humanidad nos apunta que, en situaciones de crisis social, de mudanzas y de desespero y angustia, surgen líderes capaces de implementar soluciones para salir de la crisis, como defiende Max Weber, poseedores de carisma. En

$45 \quad$ Ibidem, p. 645.

46 Cf. sobre el tema Martha Nussbaum y Amartya Sen. En su obra La idea de la justicia, Sen hace referencia a David Crocker que, en Ethics of Global Development: Agency, Capability and Deliberative Democracy, señala que como la capacidad de acción y otras capacidades constituyen la base de los derechos humanos, la justicia social y los deberes individuales y colectivos, "una ética del desarrollo examinará cómo un mundo globalizado es una ayuda o un obstáculo para que los individuos y las instituciones cumplan su obligación moral de respetar los derechos" (p. 413).

47 A. Sen, La idea de la justicia, Madrid, Taurus Pensamiento, 2009, p. 15.

48 J. M. Alexander, Capabilities and Social Justice, The Political Philosophy of Amartya Sen and Martha Nussbaum, England, Ashgate, 2008, p. 170.

49 P. Ricouer, Lo justo, Trad. Agustín Domingo Moratella, Madrid, Caparrós editores, 1995, p. 28.

50 Cf. M. Weber, Economía y Sociedad, op. cit., p. 530. 
ese sentido, el carisma sería otorgado por los seguidores y se expresaría a través del derecho en la medida que se atribuye carisma a las personas que conocen nuestra angustia, dolor y que prometen mudanzas, recompensas universalizables capaces de pasar al orden jurídico. Por lo tanto, la fuente del carisma sería nuestro propio anhelo, nuestra conciencia del derecho.

\section{Conclusiones}

En gran parte, este artículo se ocupa de examinar la actualidad del pensamiento de Max Weber que, a través de su análisis de la racionalización y legitimación del derecho, nos ayuda a comprender que, ante la crisis del formalismo del Estado de Derecho Liberal, hay que articular la racionalidad jurídica formal y material, a fin de promover la inauguración de un "derecho vivo", integrado socialmente, es decir, permitir la substitución de un procedimiento jurídico puramente formal, que funciona como un "sistema cerrado", obediente sólo a su propia lógica, por un "sistema abierto", un Derecho que consiga responder a las condiciones materiales y prácticas de la sociedad.

Partimos de la idea de que el derecho es un fenómeno social, y como tal no puede ser analizado apartado o abstraído de la sociedad, como propone el positivismo jurídico que, a lo largo de la historia, ha demostrado que sólo nos lleva a una especie de "formalismo vacío y estéril", pues el orden jurídico, en el decir de Weber, no significa "un cosmos lógico de normas «correctamente» inferidas, sino un complejo de motivaciones efectivas del actuar humano real" "51. Eso es algo que Weber ha comprendido muy bien: la sociedad no es algo "puro", sino más bien el resultado de relaciones, conflictos y cambios que proceden de los diversos aspectos o esferas de la actividad humana, como son la política, religión, economía, derecho, etc.

¿Cómo hablar de un derecho justo, de justicia material sin la comprensión de los fenómenos sociales en el Estado contemporáneo? En ese sentido, la teoría weberiana se puede convertir en un instrumento esencial en la recuperación del sentido de la realidad que se pretende investigar, a través del estudio de los más variados factores, de las múltiples lógicas y de la elaboración de los tipos ideales, que permiten entender las conexiones que son establecidas empíricamente y, con ello, un análisis complejo, rico en elementos que nos indiquen cuán próximos o distantes estamos de una sociedad justa.

En una primera conclusión, se hace evidente que para el fortalecimiento de la democracia y la consolidación del Estado de derecho hace falta un "sistema abierto" y no un sistema cerrado basado en un procedimiento jurídico puramente formal, una vez que la intervención en los elementos extrajurídicos de orden político, económico, social o ético contribuye para su progreso en el sentido de una justicia material.

De esta manera, se debe rechazar la pretensión reduccionista del papel del derecho una vez que, en el decir de Weber, "el derecho no garantiza únicamente los intereses económicos sino los intereses más diversos, desde el normalmente más elemental, la protección de la mera seguridad personal, hasta los puros bienes ideales como el propio «honor» y el de poderes divinos"52. La lógica de la racionalización sobre la funcionalidad crítica del Derecho lo sitúa como una institución propia del constitucionalismo democrático-social, en el sentido de ver el sistema jurídico no

\footnotetext{
Ibidem, p. 252.

$52 \quad$ Ibidem, p. 269.
} 
como un simple instrumento de control de las relaciones sociales, sino más bien en su condición de institución integradora y definitoria de la función socio-política.

Sin embargo, han existido y existen sistemas legales en los que la protección de los derechos no se extiende por igual a toda la población, y el contenido de dichos sistemas legales no está relacionado con la moral, como implica la versión tradicional de la teoría del derecho natural, de forma que leyes particulares contrarias a los fundamentos morales no son necesariamente inválidas. De cualquier forma, existe un contenido elemental común a los sistemas legales y la moralidad, aunque las protecciones relativas a dicho contenido pueden ser negadas a una buena parte de la población durante mucho tiempo sin destruir un sistema legal ni invalidar sus leyes.

Por eso, Weber afirma que muchos de esos sistemas legales tropiezan con el obstáculo inevitable de la contradicción entre el formalismo abstracto de la lógica jurídica y la necesidad de que se cumplan, a través del derecho, ciertos postulados materiales. Es decir, en muchos casos, vulnera "ciertos ideales materiales de justicia" por su inevitable carácter abstracto.

Finalmente, y no menos importante, hay que señalar el papel que puede desempeñar la "autoridad carismática" en hacer efectiva la justicia material en la medida en que se considera como "deber" de dicha autoridad, cuyo cumplimiento el que apoya la legitimidad carismática exige para sí, y cuya negligencia castiga. Esta aproximación entre la concepción del líder carismático, formulada por Weber, y la justicia material se da justamente porque ese líder es visto como el "héroe sabio", solucionador de todos los conflictos, promovedor de lo nuevo. El juez visto como un promovedor de la justicia social de forma efectiva a través del derecho.

Es obvio que no se está defendiendo aquí la figura del juez como líder carismático totalitario, sin restricción de poderes. Estamos cuestionando su actividad reducida a la mera tarea mecánica de aplicación de la ley y potenciando su imprescindible papel en la nueva relectura del derecho, en la actividad creadora del derecho, un nuevo derecho, un derecho justo materialmente, que lleve en consideración los factores sociales como factores legitimadores de la decisión judicial que tiene como objetivo final la paz social.

En las fechas en las que este trabajo se ha escrito, existen en España casos muy concretos de ese papel del juez como intérprete de la ley y creador de justicia en los conflictos sociales ocasionados por la venta de participaciones preferentes a clientes de entidades financieras, productos que en el fondo son derivados financieros cuyos riesgos son normalmente difíciles de entender por el ahorrador común y claramente inaceptables para la mayoría de ellos, en los procesos judiciales por la existencia de las denominadas clausulas suelo abusivas en préstamos hipotecarios o en la interpretación de la ley en los casos de desahucios por impago de cuotas hipotecarias. Todos estos casos son ejemplos de conflictos sociales donde algunos jueces han tenido que decidir si se limitan a una mera aplicación de la ley, sin tener en cuenta su impacto en la paz social, o si deben alzar su voz para denunciar su impacto y sugerir nuevas interpretaciones de ésta. Han decidido, incluso, llevar a organismos superiores la pregunta sobre si su aplicación rígida entra en conflicto con los derechos de los ciudadanos, creando con ello justicia y abriendo el camino a cambios legislativos para hacer que la ley sea justa. 